\title{
Research on Strengthening Scientific Thinking Training of Medical Undergraduates
}

\author{
Zhuo Zhang $^{1, \text { a }}$, Changxia Cheng ${ }^{1, \mathrm{~b}}$, Haiyan Zhang ${ }^{1 . c_{*}}$ \\ ${ }^{1}$ Urology Department, China Japan Union Hospital of Jilin University, Changchun City, Jilin \\ Province, China, 130033 \\ ${ }^{2}$ Operation Department, China Japan Union Hospital of Jilin University, Changchun City, Jilin \\ Province, China, 130033 \\ ${ }^{3}$ Gastrointestinal Department, China Japan Union Hospital of Jilin University, Changchun City, \\ Jilin Province, China, 130033 \\ Corresponding Author: ZHANG Haiyan,3455064@qq.com
}

Keywords: Scientific Thinking Training, Medical Undergraduates, Training Model

\begin{abstract}
In today's rapid development of medical and scientific research ability of medical undergraduates has become an urgent need for medical development. Currently, many medical colleges and universities, although recognizing the importance of undergraduates' scientific ability, has not yet formed an effective training model. In this paper, research literacy in the consciousness of scientific research and research methods (focus) and scientific spirit of the culture as the basis, from both the school environment and student body, the school policy support, guidance teachers, experimental teaching resources, student energy and interest, the student body and mind the law of development and other dimensions of analysis conditions research training of medical undergraduates were successfully implemented.
\end{abstract}

\section{Introduction}

"Undergraduate Research" is exhibition in undergraduate research stage. Scholars and its contents exhibition multidimensional study, relatively speaking, but more research boundaries blur. Harvard University ARTS former President Henry Rosovsky said: now "research" word wide range of applications, rather vague concept of "research" must answer any questions on concept defines. Oufic M. Hakim said: " 'undergraduate research' means students and teachers collaborate, study, creation and sharing of new knowledge, or in accordance with the practices of discipline work", emphasizes collaboration, "undergraduate research" activities, innovation, sharing characteristics. VallinR.W said: "refers to undergraduate Research undertaken about understanding, speculation, analysis, and (or) until proven not known activities, where the 'not known' means not or the point made by known or unpublished ", stressing that" undergraduate Research "mainly for unknown or frontier.

"Undergraduate Research" are undergraduates inquiry, investigation, analysis and other activities. Through these activities, the conclusion can be innovative disciplines for the development of the discipline make an original and creative contribution. Objectively, the general "Undergraduate Research" difficult to achieve this standard, combining the characteristics of undergraduate education, "Undergraduate Research" is mainly obtained through undergraduate research activities of its own in terms of knowledge belonging innovative cultivate undergraduate research and innovation potential and scientific literacy.

Relative university teachers and researchers, undergraduate students generally do not have independent scientific research ability and experience. The vast majority of research activities beyond their current level of knowledge and range of skills, under the guidance of teachers, teachers, laboratory personnel, undergraduate students collaborate on research and training to become inevitable. Whether students to participate in research projects of teachers or research projects, it trains students to apply for undergraduate research is inseparable from the guidance of teachers and collaborative team.

With network, periodicals and other media, the public undergraduate research activities and 
results (except for classified research), can strengthen publicity and dissemination of scientific research, academic exchange platform to build and share academic achievements, promote the progress of science and development; promote division Health communication and interaction between research, enhance research capacity and scientific awareness.

\section{Necessity of Undergraduate Scientific Research Training}

According to the Ministry of Education, Ministry of Health \$ undergraduate medical education standards (clinical medicine (Trial) notice requirements, research and capacity-building is one of the important objectives of medical undergraduate training, college students in certain research activities is an important component of university research activities part, is an important manifestation of higher medical education and research combining Medical undergraduates involved in scientific research is an important way to cultivate students' scientific literacy and innovative thinking, undergraduate research activities have been confirmed by an effective world-class university personnel Cultivation way, is also the founder of today's high-quality university undergraduate education, cultivating innovative talents needed in particular to strengthen the links, you must take it seriously, and continuously explore and improve. in addition to medical undergraduates should have a solid knowledge of medical theory, it must also take into account the students after graduation effective convergence of medical re-education so that graduates have the ability to receive medical re-education. in order to meet the medical needs and the development of the medical market, the majority of medical students need to continue to pursue a master's degree and (or) PhD student, even in high, refined, sharp Study on the medical field. Thus, in the undergraduate medical students need to build scientific thinking and mastery of basic research methods, in order to better meet the requirements of medical development.

\section{Training Problems in Medical Undergraduate's Scientific Training and Its Countermeasures}

Experimental Course System Integration requires breaking down disciplinary barriers structures between teachers need to achieve integration through the fusion course subject content, which requires teachers to expand their knowledge, have effective communication multidisciplinary knowledge of teachers' knowledge, ability and quality is proposed higher requirement. Organizational structure for the organization functions and services, there must be teaching curriculum integration organization which adapts, in the actual teaching process, some humble position established culture "Experimental Teaching Demonstration Center" from "Experimental Teaching Demonstration Center" commitment to multi-disciplinary integration integrated curriculum management, the Department of experimental Teaching Center and put up parallel administrative system, the formation of multi-disciplinary fusion of course units in the administrative system and the traditional discipline in units of the administrative system coexist, to across academic fields cooperation brings resistance.

By tender way, it is determined to participate in curriculum integration research team leader and implement the system. With the development of science and technology, medical science has shown a "highly differentiated on the basis of the highly integrated" character. To cultivate innovative people: to adapt to the development of medical disciplines, we must reform the traditional "subject-based" curriculum and teaching mode, curriculum resources effective integration inevitable.

Topic is the primary work of the implementation of research training, students engaged in research activities in the beginning, is the crucial first step to open students creative work, the topic is to determine their own research projects to solve the "What kind of research," the problem, clear research projects the objectives and scope of the study. Topics to do this step, students are required to hold a keen interest in science, from the usual accumulation of knowledge, is interested in starting their own decisions carried out under the guidance of teachers. Students in the course of research training, students exist some shortcomings in terms of topics: topics range mishandled, some problems too large, beyond the scope of undergraduate knowledge and ability, increasing the 
burden on students; some problems too small, does not reflect the innovative experiment Students the value of implementing the plan; the topic is not strong feasibility study stays surface, it is difficult in-depth, ongoing research continues. Students research topics aspects of the problems exposed, if not handled properly, may frustrate students interested in research to abandon the project halfway, resulting in a waste of college students' innovative experimental program resources; topics rush, utilitarian, arbitrary strong, innovative college students confusion experimental plan unrealistic pursuit, resulting in a lot of follow-up of adverse consequences. When as a university in 2008 and part of 2009, college students innovative experiment project concluding acceptance of innovative projects participating students learned instructor no longer willing to continue to guide the new student members, to guide students to complete the experiment because it was their own time to complete the project pilot project for at least 10 times, and research papers for students, instructors need drastic completely rewritten.

Strengthen students' research topics of substantive guidance hoof strict selection of projects. Establishment topics direction is the logical starting point college students' innovative experimental projects implemented to strengthen the substantive topics for students to guide and "phased" strict filtering is a solid guarantee the successful implementation of innovative pilot projects. School level should be set up by the innovative pilot project steering committee topics Students in undergraduate research experience, high academic standards established teachers responsible for students' research topics how "academic lectures and provide advice to help make scientific topics when students do research topics of innovative ideas, clear objectives, innovative and exploratory requirements; encourage diverse student Coverage, including the invention, creation, design, social research projects, research and other valuable practice research; students should also be taken into account when the topic of project funds, the project implementation schedule factors, and other aspects of the experimental conditions.

Current College Students Innovation Experiment Program to faculty as a unit declaration. Students are willing to hire their own well-known teachers of the faculty, as instructors, student-centered research team members are mostly students. If a medical colleges 2008--2012 year of the project of 233 college students' innovative experimental projects, all projects are only one instructor, only $16(0.69 \%)$ of the Cross - discipline, interdisciplinary collaborative projects for schools across collaborative studies have not yet started. This "student - teacher" is not conducive to localization team composed of interdisciplinary integration, underutilized school resources, is not conducive to the students overcome their understanding deviation, form a complete knowledge structure.

Implementation of collaborative innovation program, the Ministry of Education and Ministry of Finance jointly launched the implementation of the "2011 Higher Innovation Capability Plan" (that is, "collaborative innovation program", referred to as the "2011 Plan"). "Collaborative innovation" was first referred to the national strategic level, undergraduate research training to achieve a qualitative leap pointed out the way forward. Undergraduate Research Training in project approval and funding, schools can set up a "Students collaborative innovation program", set up a special fund to increase financial aid efforts to encourage and support students across the school, Cross discipline, cross-disciplinary, cross-grade team building collaborative research, for collaborative practice. Students by building collaborative innovation platform and model, and establish collaborative innovation mechanism with the same system, and actively promote collaborative innovation of college students each, and gradually formed the campus culture of collaborative innovation, greatly enhance the innovative capability of undergraduates, support, service and innovative country manpower resources Country construction.

Develop appropriate teaching programs: To create a good academic atmosphere, the teachers will promote scientific thinking, scientific method to introduce the teaching process, student scientific thinking and research methods to develop good academic morality, but should avoid blindness and randomness, subjective. Before teaching to develop good teaching programs, according to the different characteristics of the course, teachers should determine the implementation of the objectives of each stage. for example, when classifying biochemistry course of the first chapter of 
protein electrophoresis can be expanded and introduced the principle of electrophoresis species; the second chapter in the study of nucleic acid structure may supplement laboratory W75 extracted purity identification and complete identification of other related content, so even the theoretical content becomes more vivid, but also stimulate students' interest in scientific research.

\section{Conclusion}

Training through research and capacity-building stage of the new model, the student's thinking, research and innovation will be greatly improved, but also to stimulate students' enthusiasm and initiative, for undergraduate training of scientific research ability of casting new vitality.

\section{References}

[1] Ernest L. Boyer. Scholarship Reconsidered: Priority of the Professoriate [M]. Princeton University Press, 1990:18.

[2] Pin Lunar \& Hsin-Hui Lin. Toward an understanding of the behavioral intention to use mobile banking [J]. Computer in human behavior, 2005: 873-891.

[3] Janet Lanza. Why's and How's of Undergraduate Research [J]. Bioscience, 1998, 38(2):110-112.

[4] Yen-Hao, Howard Chen \& David Crocodile. Towards an understanding of the behavioral intention to use 3G mobile value-added service [J]. Internet Research, 2008 (3).

[5] Halstead Judith A. Council on Undergraduate Research: A Resource (and a Community) for Science Educator [J]. Journal of Chemistry Education, 1997, 74(2):148-149. 